\title{
JOURNAL.RU
}

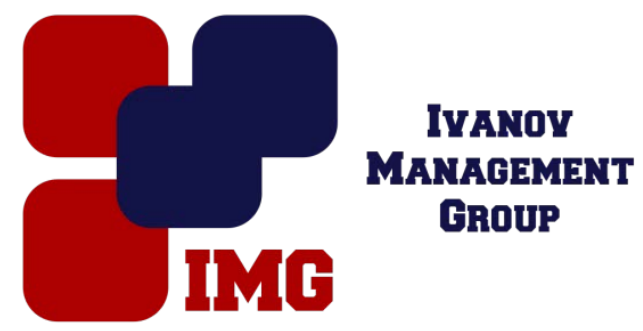

Kornilova I.

Tyumen State University

Tyumen, Russia

doi: 10.18411/lj-31-03-2017-1-02

idsp 000001:lj-31-03-2017-1-02

\section{Sociological research methods of real estate market}

\section{Annotation}

In recent years, the existing system of real estate market research, specialists inthe field of Sociology enriched with new direction-specific sociological methods. These methods are used, both independently and with the main methods of research of the real estate market, including: mathematical statistics, analysis, market monitoring, etc.

We can say that applying new sociological methodsmake possible formation and testing working hypotheses, also clarifying the General opinions of participants regarding the analysis groups together objects into homogeneous groups. In addition, these methods allow the characteristics of the relationship specialists to classify objects in quality, receiving numerous zoning estimation parameters.

Keywords: real estate, sociological methods, market survey, questionnaire.

Sociological research methods are more perfect tool of analysis of real estate market. Today specialists actively used interviews with experts and consumers.

2 In our opinion, without modern sociological methodscannot be optimally and accurately understandingof the demand and its features in the real estate market.

Using of sociological methods reflected an independent tool when creating assortment structure by: -appointment of non-residential premises; -apartments layout apartments; -appointment of non-residential premises; -infrastructure planning; formationof conditions policy in the field of mortgage and installment [1].

It is actual to create working hypotheses when you apply modern sociological methods. In our opinion, If you are implementing a series of expert interviews you can increase the quantity and quality of standard sources of primary data about the real estate market, transactions and demand.

With optimal behaviour of the interviewer and also his high training, it is possible to obtain unique information about participating companies and individual companies.Sociological research methods, in our view, analyze principles of perception and rejection of information about any real estate. 
In addition, there is a specific kind of information that cannot be obtained without using of the sociological methods of analysis. You can receive informal and non-public information about any real estate only according to the results of collection work and analysis of sociological information.

In our view, for a comprehensive study of the real estate market it is necessary to combine optimallysuch methods as:

- statistical;

- sociological;

- mathematical.

The using of various modern sociological methods allows you to identify factors that affect on improving real estate market, it helps to make search fuller and toforecast existing real estate market.

Criteria for assessment of real estate consumers, as factors on which they perceive the real estate market in General may research only through the intelligent application of various methods of sociological research.

In order to take the specific management decisions in the field of real estate, it is important to understand the needs of the main segment of consumers and buyers of real estate. It is important to know the types, numbers, characteristics and to check periodically an implementation processes for purchasing real estate, alsoit'sinfluencing factors, to monitor the emergence of new objects, to know how to know how certain companies and objects are perceived at the moment.

In addition, in carrying out of sociological methods of analysis of the real estate market, it is important to focus on the weaknesses and strengths of the market, competitors, the perceptions of the target groups of consumers.The using of sociological methods in case studies of real estate market allows you to find a unique tool, as well as a distinctive idea, ensuring the victory in the battle for a target audience [3].

Application of sociological research methods helps get the necessary operational information on external and internal factors of consumer behavior, as well as to evaluate the decision-making process, the total consumption of mindfulness.

By using these methods, it is possible to identify promising trends of the real estate market. At this point in the real estate market is constantly increasing demand for various sociological studies.

However, this trend was actively improving during the stagnation of the market that has a stable, sustainable improvement to date, regardless of the price increases, a situation of active demand.

Using of sociological methods of the analysis of real estate market helps to know the views of the representatives of the target groups, as well as predict the development of the market, identify the success of future advertising companies and overall popularity on the market.

Today, in General, there is little significant objects in the real estate market, which before would not have implemented large-scale marketing research using sociological methods.The technology research of the real estate market in sociological methods play an important role. 
These procedures and rules of market analysis form the link between hypotheses, facts and theories.

It is important to be aware that sociological methods are scientific procedure, in which special technologies and social tools areused.[2].

There are four methods of empirical research in modern sociology:

- observation;

- poll;

- experiment;

- analysis of documents.

In our view, the most popular methods of researching real estate market are :

- questionnaires, various polls;

- focus groups;

- underlying structured interviews.

The main results of the sociological research can determine the exact location of analyzed company on the real estate market, as well as a direction for the future successful development. Using of various sociological methods allows to obtain some unique information about consumers, market, competitors. This research helps to assess a success of advertising campaigns on the real estate market.

The main feature is the ability to obtain information in a clearly limited period of time.That is why more and more construction companies, as well as real estate agencies and other market participants help shape the advertising campaign, as well as go-tomarket strategy for a new project based on the receipt of comprehensive market research using numerous sociological methods of analysis. In the moment there is activeimprovement of analys' directions of real estate market, which extends and deepens understanding of processes and a situation on market, which helps increase quality of recommendations and forecasts of analysts to increase business success.

Under current conditions in the real estate market, in case of increase proposals, quite an important aspect of work of the developer reflects fast and guaranteed sale of real estate under construction [3].

This implementation might achieve using optimal building concept, which will be mitigated by numerous features of the projects.

Forming hypotheses of possible construction of some of the plot is based on the results of interviews with specialists implemented real estate companies, which are engaged in the construction and real estate sales, experts specific departments improve developer companies, potential target groups and real estate consumers.

The main task of creating hypotheses of sociological research methods is minimization of profit from the sale of real estate, to avoid liquidity facilities that are able to lower sales volumes, it will negatively affect the financial results of some project.

Generally, using of sociological methods aimed at obtaining concrete results:

- analysis of factors that affect consumer behavior on the existing real estate market, among them: regional characteristics of macro-and microeconomic;

- characteristics of the target audience; 
- real estate market segmentation in terms of potential and actual users;

- analysis of the possible behaviour of consumers;

- analysis of market capacity in terms of prediction;

- analysis of the consumption and preferences;

- implementation of research conduct of the respondent in the case of the choice of real estate property;

- testing of promotional materials;

- analysis of the respondent's personal experiences of cooperation with various market participants;

- analysis of the awareness and the success of an advertising campaign;

- characteristics of the target audience on the parameters of the use and purchase of real estate;

- description of psychographic characteristics present target audience.

In recent years, the existing system of real estate market research, specialists in the field of Sociology swelled new direction-specific sociological methods. These methods are used, both independently and with the main methods of research of the real estate market, including: mathematical statistics, analysis, market monitoring, etc.

It can be said that when applying new methods in sociological and may be testing working hypotheses, as well as clarifying the General opinions of participants regarding an analysis groups together objects into homogeneous groups. In addition, these methods allow characteristics of the relationship specialists to classify objects in quality, receiving numerous zoning estimation parameters.

\section{Литература}

1. Diaghilev n. Zhuravleva, l. a. methodological bases for application of sociological research//Herald of the Chelyabinsk State University, no. 4, 2012. 75-79 p.;

2. Sedoed n. s. a. Demenjuk dignity of sociological research methods//problems of modeling of social processes. Materials 2-th all-Russia scientific — practical Conference with international participation, 2016. 711-712 p.;

3. Yurova e. s. features of sociological method in studies of markets//actual problems of market research. Collection of articles by the all-Russian scientificpractical Conference, 2016.226-231 p. 